\title{
Lichen elemental content bioindicators for air quality in upper Midwest, USA: a model for large-scale monitoring
}

\author{
Susan Will-Wolf ${ }^{1,4}$, Sarah Jovan ${ }^{2}$, and Michael C. Amacher ${ }^{3}$
}

\begin{abstract}
Our development of lichen elemental bioindicators for a United States of America (USA) national monitoring program is a useful model for other large-scale programs. Concentrations of 20 elements were measured, validated, and analyzed for 203 samples of five common lichen species. Collections were made by trained non-specialists near 75 permanent plots and an expert near nine air monitoring sites. Flavoparmelia caperata (most frequent) and Physcia aipolia/stellaris between them represented the full range of local forest cover and pollution load. Evernia mesomorpha (values saturated at intermediate pollution), Parmelia sulcata, and Punctelia rudecta (both difficult for non-specialists) were less useful. Conversion models (GLM or regression) rendered elemental data equivalent between species. $\mathrm{Al}, \mathrm{Cr}, \mathrm{Cu}, \mathrm{Fe}, \mathrm{Hg}, \mathrm{N}$, and $\mathrm{S}$,


plus composite indexes from them, were linked with local air pollution based on correlations with directly measured $\mathrm{N}$ and particulate matter as well as from PCA; elements were weakly correlated with modeled pollution estimates. Lichen $\mathrm{Hg}$ had no other useful surrogates. Invoking multiple causation and scale-dependence helped address several issues of interpretation, for instance conflicting bioindicator value of $\mathrm{Al}$ and $\mathrm{Fe}$ from literature.

Keywords: bioindicator; element; lichen; metal; nitrogen; pollution; scale-dependence; sulfur

\section{Introduction}

Biomonitoring response to air pollution is an important component of evaluating the health of biological systems (e.g., for lichens Fenn et al. 2003; Nimis et al. 2002). Estimation of local air quality from elemental concentrations in lichens or mosses naturally growing in situ (passive monitoring as opposed to active monitoring with transplants: Garty 2002) is a classic technique (Ferry et al. 1973; Martin \& Coughtrey 1982) with wide current usage (e.g. Donovan et al. 2016; McMurray et al. 2015; Paoli et al. 2014) to complement costly instrument monitoring.

Elemental biomonitoring well represents relative local pollution loads, as compared with instrument measurements (e. g. Bargagli \& Mikhailova 2002; Root et al. 2015), although accuracy of quantitative calibration varies (e. g. Bargagli 2016; Bari et al. 2001; Boquete et al. 2015; Cercasov et al 2002; Vestergaard et al. 1986). Elemental bioindicator species should be relatively pollution-tolerant, widespread, and amenable to collection (e.g. Conti \& Cecchetti 2001; Puckett 1988; Wolterbeek 2002). Elemental accumulation rates can differ between lichen 
2 63

species; conversion between species (e.g. Karakas \& Tuncel 2004; Root et al. 2013; Sloof and Wolterbeek 1993) can provide equivalent elemental data.

Our protocols were designed for large-scale studies where multiple target species are likely and simplicity plus cost-effectiveness facilitate implementation. Our general objective for the full project (located in upper Midwest, USA) was to recommend improved practices for elemental biomonitoring using in-situ mosses or lichens. Our objectives for this aspect of the full project were to: 1) evaluate elemental concentrations in multiple lichen species from nonspecialist collectors; 2) develop conversion models between species; 3) calibrate lichen elemental data to measured values; and 4) evaluate lichen-indicated air quality across the study region. In two other aspects of this project, Will-Wolf et al. (2017a) assess the impact of variation in protocols and staff expertise on data quality, and Will-Wolf et al. (2017b) evaluate applications of protocols and bioindicators in eastern United States of America (E USA) for the United States Department of Agriculture Forest Service Forest Inventory and Analysis Program (FIA) program. Lichen elemental bioindicators for two other E USA projects (Will Wolf et al. 2014, 2015b) used similar protocols, but only expert staff.

\section{Methods}

\subsection{Study Region and Environmental Variables}

The $241,800 \mathrm{~km}^{2}$ project area includes USA states Wisconsin and parts of adjacent Illinois, Iowa, and Minnesota (Fig 1). It mostly extends across two Bailey ecoregions (Bailey et al. 1994; Cleland et al. 2005): Laurentian Mixed Forest (province 212) and Eastern Broadleaf 


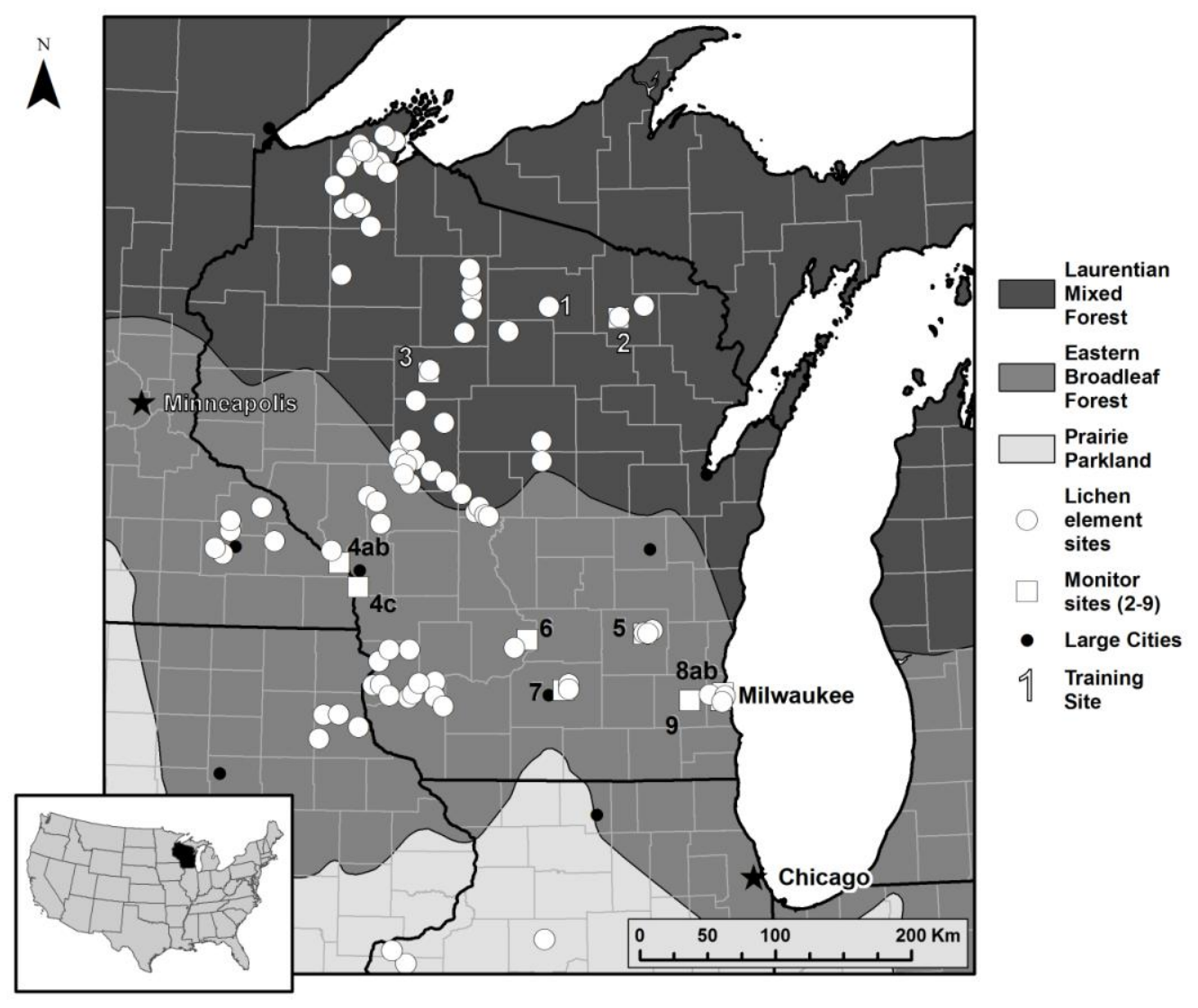

Figure 1. Locations of lichen sites and instrument monitor sites. Wisconsin, marked in the USA inset, is in the center with Minnesota west, Iowa southwest, and Illinois south.

Forest (province 222); three southern (Illinois) plots are in Prairie Parkland (province 251).

Broadleaf Forest has more fragmented deciduous broadleaf forests interspersed with agricultural land; Prairie Parkland now has sparse deciduous broadleaf forests in an agricultural landscape. Environmental variables represent location, climate, land cover, and modeled pollution deposition (Table 1; Supplementary Document 1). Lichen elemental concentrations and species distributions were correlated with land cover in a subset of the project area (Will-Wolf et al. 
81 Table 1. Site characteristics by ecoregion; most useful environmental variables. Variables in bold 82 had the strongest relationships with lichen elemental data.

Laurentian Mixed

Forest

$\mathbf{N}=\mathbf{4 0}$
Eastern Broadleaf

Forest

$\mathbf{N}=\mathbf{4 0}$

$\operatorname{avg}$
Prairie Parkland

$\mathbf{N}=\mathbf{3}$

avg range

\begin{tabular}{rcccccc} 
Environmental Variable & avg & range & avg & range & avg & range \\
\hline Geography, Climate & & & & & & \\
Latitude, deg N & 45.66 & $44.32-46.77$ & 43.55 & $42.77-44.53$ & 41.37 & $41.28-41.45$ \\
Longitude, deg W & -90.63 & -91.51 to -88.57 & -90.59 & -92.55 to -87.90 & -90.40 & -90.89 to -89.54 \\
Elevation, m & 1227.90 & $442-1732$ & 820.69 & $190-1200$ & 740.33 & $713-785$ \\
Min annual temp, deg C & -0.55 & -1.49 to 0.93 & 2.15 & $0.22-4.49$ & 4.64 & $4.27-4.97$ \\
Max annual temp, deg C & 11.30 & $9.93-13$ & 13.24 & $12.4-14.4$ & 15.58 & $15.53-15.66$ \\
Mean annual temp, deg C & 5.38 & $4.27-6.93$ & 7.70 & $6 / 34-8.99$ & 10.11 & $9.91-10.32$ \\
Mean annual ppt, mm & 822.80 & $773.4-897.6$ & 870.34 & $830.7-943.6$ & 932.27 & $930.8-933.1$
\end{tabular}

Land cover, $\%$

$\begin{array}{rcccccr}\text { Forest Cover } & 88.35 & 48.4-100 & 46.16 & 0.8-95.6 & 20.54 & 7.8-36.2 \\ \text { Agricultural Cover } & 5.80 & 0-50.7 & 30.83 & 0-81.5 & 74.23 & 58.5-87.9 \\ \text { Developed Land Cover } & 3.30 & 0-22.1 & 16.35 & 0.73-99.0 & 4.15 & 3.30-5.09\end{array}$

Modeled air pollution,

$\mathrm{kg} / \mathrm{ha} / \mathrm{yr}$

$\begin{array}{rcccccr}\text { SO }_{4} \text { wet deposition } & 6.33 & 5.47-8.55 & 7.81 & 6.10-9.96 & 7.95 & 7.51-8.78 \\ \text { Hg wet deposition } & 8.63 & 7.41-10.23 & 11.11 & 9.20-12.95 & 10.45 & 10.3-10.7 \\ \text { S total deposition } & 3.68 & 3.16-4.45 & 4.79 & 3.65-7.58 & 5.51 & 5.42-5.62 \\ \text { N total deposition } & 10.32 & 8.08-16.30 & 14.42 & 7.83-19.43 & 11.76 & 11.4-12.5\end{array}$

Pollution Indices

$\begin{array}{rrrrrrr}\text { Lichen } \mathbf{N}+\mathbf{S} & 1.09 & 0.51-2.54 & 1.63 & 0.97-2.64 & 1.22 & 0.44-2.10 \\ \text { Lichen } 5 \text { metals } & 1.28 & 0.66-2.65 & 1.45 & 0.89-2.50 & 1.00 & 0.63-1.63\end{array}$


2011, 2015b); similar links were investigated at this larger spatial scale. Measured pollutants for 2008-2013 were from 11 instrument monitoring stations at eight monitor sites (2-9 on Fig. 1) linked with national networks (Supplementary Document 2).

\subsection{Target species, field data collection, and measurement}

Five macrolichen species common in eastern North America (E NA: Brodo et al. 2001) were collected: Evernia mesomorpha Nyl. (acronym Evemes; small/medium size fruticose growth form), Flavoparmelia caperata (L.) Hale (acronym Flacap: large foliose), Parmelia sulcata Taylor (acronym Parsul; medium foliose), Physcia aipolia (Ehrh. ex Humb.) Fürnr. var. aipolia and P. stellaris (L.) Nyl. combined (acronym Phyaip; small foliose, tightly appressed), and Punctelia rudecta (Ach.) Krog (acronym Punrud: large foliose). Flacap and Punrud were used in two recent E USA studies (Will-Wolf et al. 2014, 2015b) and all but Phyaip have been used in other studies in the region (Will-Wolf et al. 2017a).

Lichens were collected by FIA field staff with no prior experience with lichens, who survey permanent plots on a preset 10-year rotation (USDA FS 2015), and by professional lichenologist Susan Will-Wolf (the expert). Field staff were trained (at site 1, Fig. 1) for one day by the expert (details in Will-Wolf et al. 2017b). Field staff collected lichens SeptemberNovember 2013; the expert collected in Summer-Fall 2013 from temporary sites near monitor sites $2-9$ on Fig. 1 (Supplementary Document 2).

Collection areas were forest openings or edges with 20-50\% canopy near permanent FIA plots (no destructive sampling on plots: USDA FS 2015) or at temporary sites with similar characteristics. The moderately narrow range of relatively open canopy reduced habitat variability (e. g. Gandois et al. 2014), allowed penetration of air pollution, and still represented 
forest conditions. Areas affected by local chemical contamination (e. g. adjacent to active agricultural fields, roads, or lawns) were avoided. Target species were collected from any natural standing (live or dead) woody stem or branch $0.5 \mathrm{~m}$ above the ground and within reach.

The field staff collection goal was two samples at each site; replicates of multiple species were collected at intervals. The expert collected replicate samples of each target species present at a site, plus a bulk Flacap sample for internal reference (Will-Wolf et al. 2017b). Samples for this study followed rigorous collecting and handling protocols (Will-Wolf et al. 2017a) to avoid contamination. Adequate samples included $\geq 1$ gr air dry weight for one species, appearing healthy, and composited from $\geq 6$ different substrates within a 200-500m range (averages across within-site variation). Samples were handled in the field and lab (by the expert) wearing clean nitrile gloves, collected into certified chemically clean bags, air-dried, and kept cool and dry before measurement. Equipment was wiped with alcohol. Sample elements (listed by standard codes: IUPAC 2014), plus a certified external standard (IAEA-336 pre-ground Evernia prunastri from rural Portugal: IAEA 2014) and the internal reference, were measured at the Soil and Water Analysis Lab, Logan Forestry Sciences Lab, USFS Rocky Mountain Research Station, Logan, Utah, USA. C, N, S, and Hg were measured with combustion analysis, while 23 elements were measured by chemical digestion and ICP-OES (Supplementary Document 3).

\subsection{Elemental Data Validation and Conversion between Species}

Validation of elemental data was based on values below detection limit (BDL) and variability of replicates. Extreme outlier values $(>5 \mathrm{x}$ the next higher value) were removed before validation (measurement error assumed). Replicate variability was calculated as relative standard deviation (rSD: $100 *$ standard deviation $\sigma$ divided by |mean $\mu \mid$; e. g. Halleraker et al. 1998), 
equivalent to coefficient of variation (CV) when $\mu$ is positive. Average rSD was calculated for replicates of the external standard, the Flacap internal reference, Flacap from field sites, and post-grinding lab splits of all species. Validated elements had $<5 \%$ of values BDL and average $\mathrm{rSD} \leq 25 \%$ for all sets of replicates. Cut-offs in the literature for data reliability are $10-50 \% \mathrm{rSD}$ or CV (e. g. Frati et al 2005; Gailey \& Lloyd 1986; Loppi et al 2002). For validated elements, BDL values were replaced by $1 / 2$ the smallest accurately detected value.

Conversion of each species' data to equivalence with Flacap used data from all sites having both species. Linear regression of species averages for sites (Flacap the independent variable) and General Linear Model (GLM) univariate analysis of sample values with species and site as fixed independent factors were calculated in SPSS v23.0 (SPSS 2015). Logarithm base 10 transformed $(\log 10)$ data corrected for data distribution issues as necessary. Model strength was judged from homogeneity of variances (GLM) and probability (p) values. Flacap data violated the regression model assumption of no measurement error for the independent variable, so a GLM model (measurement error assumed) was selected when $\mathrm{p}$ values were similar, and a regression model with $\mathrm{p}>0.005$ was described as weak, in case measurement error of Flacap had inflated model strength. Models from regression and/or log 10 data with notably lower $\mathrm{p}$ values were interpreted as indicating the relationship was non-linear. The second species' elemental concentrations were converted to equivalence with Flacap values using the strongest model. Site averages were calculated from converted data.

\subsection{Elemental Data Analysis}

Calibration of expert samples to measured data from air monitoring sites (2-9, Fig. 1) used monitor site variables for particulate matter (PM) and monitored elements. Each was often 
measured in different ways, for example both "Cadmium PM (particulate matter) 2.5 (particle size in microns) LC (local conditions)" and Cadmium PM10 LC might be measured. For the most frequent variable both measured and ranked values were tested. Values were also ranked for each type of variable for each element or compound; ranks were averaged for each monitor site to increase sample size (Supplementary Document 2). We then correlated (SPSS 2015) composite monitor site variables with lichen elemental data from nearby sites.

Patterns of association between validated elements were explored with principal components analysis (PCA) and pairwise correlations. PCA of average site values for each element was conducted in PC-ORD v.6 (McCune \& Mefford 2016); outcome was compared with randomized runs. Pairwise correlations between elements by sample or site, plus simple and partial correlations (SPSS 2015) with environmental variables, also suggested sources or arrival modes. Many statistical tests were performed but elements and variables were often correlated with each other. To qualitatively account for experiment-wide error, any result with $\mathrm{p}$ value $0.01<\mathrm{p}<0.05$ was considered weak (includes species conversion models described in section 2.3)

\section{Results}

\subsection{Elemental data collection and validation}

In total 231 field samples were collected; 221 were measured for 26 elements in spring 2014. Field staff collected 146 samples near 70 of 81 permanent plots visited (86\%) and 75 searched (93\%), with two or more target species near $52(74 \%)$ searched plots (ten not measured: only non-target species or too small). An additional 75 samples were collected and measured by field staff from the training site or by the expert at 13 temporary lichen sites near eight monitor sites. Plots equally represented the two most prevalent ecoregions and spanned the full (NE-SW) 
176 climate gradient and a long pollution gradient (Table 1), though they were unevenly spaced (Fig.

177 1). About $85 \%$ of 30 individuals of sampled Phyaip from five sites were assigned to Physcia

178 aipolia; $\sim 15 \%$ (from three of those sites) were assigned to P. stellaris. Vouchers for all species

179 are deposited in WIS. Twenty elements were validated for analysis (Table 2). Six (As, B, Ba,

180 Mo, Se, Si) were excluded, with $>5 \%$ BDL and/or $\mathrm{rSD}>25 \%$ from $7-8$ replicates of the standard

181 and/or internal reference. Average rSD for field replicates or lab splits confirmed those stronger

182 results (Supplementary Document 3). S from digestion/ICP-OES was used for analyses; it had

183 smaller rSD for field replicates and more sites with data than S from combustion.

184 This study analyzed data for 203 measured samples from 83 sites (original data and

185 information on sites in Will-Wolf et al. 2017b). Will-Wolf et al. (2017a) excluded 18 samples

186 from analyses because of poor quality validated data for several elements. Most excluded

187 samples also had field sample quality issues: sample composited from too few substrates, very

188 small, or with external contamination, including a novel possible soil dust signal from high $\mathrm{Ca} / \mathrm{Sr}$

189 and low values of pollution elements (Supplementary Document 4, sections S4.1, S4.3).

190

191

\subsection{Conversion of lichen species data and calculation of Pollution Indices}

Most species and elements required data conversion for equivalence with Flacap (Table

193 2; model parameters and formulas in Supplementary Document 5). Relationships between

194 species appeared nonlinear (regression and/or log10 data gave the strongest model) for most

195 elements. The strongest model (of up to eight) had the lowest $\mathrm{p}$ value, the most homogeneous

196 variances, and the weakest site x species interaction (GLM results). Conversion was from the

197 difference between Estimated Marginal Means (EMMs) for a GLM model or the linear

198 regression model formula applied to the second species. For Evemes, Phyaip, and Punrud a few 
199 Table 2. Summary of models for conversion of data from other lichen species to equivalence

200 with data from Flacap (total number of sites with both species in parentheses). Original data were

201 used unless noted. Abbreviations: excl. = excluded; GLM = univariate general linear model;

202 regress $=$ regression model; $w \mathrm{k}=$ model $\mathrm{p}$ value $0.01<\mathrm{p}<0.05$

\begin{tabular}{|c|c|c|c|c|}
\hline Element & $\begin{array}{l}\text { Evemes to Flacap } \\
\qquad(\mathrm{N}=13)\end{array}$ & $\begin{array}{l}\text { Parsul to Flacap } \\
\qquad(\mathrm{N}=10)\end{array}$ & $\begin{array}{l}\text { Phyaip to Flacap } \\
\qquad(\mathrm{N}=14)\end{array}$ & $\begin{array}{l}\text { Punrud to Flacap } \\
\qquad(\mathrm{n}=13)\end{array}$ \\
\hline & & & Regress, 1 site & \\
\hline \multirow[t]{2}{*}{ Al } & GLM, 3 sites excl. & GLM, $\log 10$ data & excl. & Regress, 2 sites excl. \\
\hline & GLM wk, 2 sites & & & NOT NEEDED \\
\hline \multirow[t]{2}{*}{ tC } & excl. & GLM & GLM & (GLM), 2 sites excl. \\
\hline & & & & GLM, $\log 10$ data, 3 \\
\hline \multirow[t]{2}{*}{$\mathbf{C a}$} & GLM, 2 sites excl. & GLM & GLM & sites excl. \\
\hline & GLM, $\log 10$ data, 2 & & & NOT NEEDED \\
\hline \multirow[t]{2}{*}{ Cd } & sites excl. & Regress, $\log 10$ data & GLM, $\log 10$ data & (GLM), 2 sites excl. \\
\hline & Regress, 2 sites & & NOT NEEDED & NOT NEEDED \\
\hline Co & excl. & GLM, $\log 10$ data & $(\mathrm{GLM})$ & (GLM), 2 sites excl. \\
\hline \multirow[t]{3}{*}{$\mathrm{Cr}$} & GLM, 2 sites excl. & GLM, $\log 10$ data & GLM, $\log 10$ data & Regress, 2 sites excl. \\
\hline & NOT NEEDED & & & \\
\hline & $(\mathrm{GLM}), \log 10$ data, & & & \\
\hline \multirow[t]{2}{*}{$\mathrm{Cu}$} & 4 sites excl. & GLM, $\log 10$ data & Regress & GLM, 2 sites excl. \\
\hline & & & Regress, 1 site & \\
\hline \multirow[t]{2}{*}{$\mathbf{F e}$} & GLM, 2 sites excl. & GLM & excl. & Regress, 3 sites excl. \\
\hline & & & & GLM, $\log 10$ dat, 2 \\
\hline \multirow[t]{2}{*}{ tHg } & GLM, 2 sites excl. & GLM & GLM & sites excl. \\
\hline & & & GLM, L10 dat, 1 & \\
\hline $\mathbf{K}$ & GLM, 2 sites excl. & GLM, $\log 10$ data & site excl. & GLM, 2 sites excl. \\
\hline
\end{tabular}




\begin{tabular}{|c|c|c|c|c|}
\hline \multirow[t]{2}{*}{ Mg } & Regress & Regress & GLM, $\log 10$ data & Regress, 2 sites excl. \\
\hline & & & Regress, 1 site & Regress wk, $\log 10$ \\
\hline \multirow[t]{2}{*}{ Mn } & Regress & Regress & excl. & data, 2 sites excl. \\
\hline & & & Regress wk, $\log 10$ & \\
\hline \multirow[t]{2}{*}{ tN } & GLM, 2 sites excl. & Regress & dat, 1 site excl. & Regress, 2 sites excl. \\
\hline & GLM wk, $\log 10$ & & NOT NEEDED & DO NOT \\
\hline \multirow[t]{2}{*}{$\mathbf{N a}$} & data, 2 sites excl. & Regress & $(\mathrm{GLM})$ & CONVERT \\
\hline & GLM wk, L10 data, & & NOT NEEDED & Regress, $\log 10$ data, \\
\hline \multirow[t]{2}{*}{$\mathbf{N i}$} & 2 sites excl. & GLM wk & (GLM), 1 site excl. & 2 sites excl. \\
\hline & GLM wk, $\log 10$ & & & NOT NEEDED \\
\hline \multirow[t]{2}{*}{$\mathbf{P}$} & data, 2 sites excl. & GLM, $\log 10$ data & GLM, L10 data & (GLM), 3 sites excl. \\
\hline & GLM, $\log 10$ data, 2 & NOT NEEDED & & \\
\hline \multirow[t]{2}{*}{$\mathbf{P b}$} & sites excl. & (GLM) & GLM, $\log 10$ data & Regress, 2 sites excl. \\
\hline & Regress, 2 sites & & & NOT NEEDED \\
\hline \multirow[t]{2}{*}{$\mathbf{S}$} & excl. & GLM & GLM & (GLM), 3 sites excl. \\
\hline & GLM wk, 2 sites & & & NOT NEEDED \\
\hline \multirow[t]{2}{*}{$\mathrm{Sr}$} & excl. & GLM, $\log 10$ data & GLM, $\log 10$ data & (GLM), 2 sites excl. \\
\hline & Regress wk, 3 sites & & GLM wk, $\log 10$ & \\
\hline $\mathbf{Z n}$ & excl. & GLM, $\log 10$ data & data & Regress, 2 sites excl. \\
\hline Data & Nonlinear for $55 \%$ & Nonlinear for $65 \%$ & Nonlinear for $60 \%$ & Nonlinear for $55 \%$ \\
\hline pattern & of elements & of elements & of elements & of elements \\
\hline
\end{tabular}

205 of the sites with both species were excluded to achieve a stable conversion model: the most

206 polluted Evemes sites excluded for most elements, a Phyaip site excluded for five elements, two

207 to three moderately polluted Punrud sites excluded for most elements. No site was excluded for 208 more than one species pair. Evemes pollution tolerance was exceeded at excluded sites; Phyaip 
and Punrud unexplained anomalous data drove site exclusion (Supplementary Document 5). Data excluded for conversion models were excluded for other analyses. Ranges of site averages with converted data were similar to Flacap alone (Supplementary Document 6). Within-site variability was higher for converted data, but exceeded $25 \%$ of average only for $\mathrm{Cd}, \mathrm{Mn}, \mathrm{Na}, \mathrm{Ni}, \mathrm{Pb}, \mathrm{Sr}$, and Zn. Range of within-site replicates after conversion was mostly $<10 \%$ of full range.

Two combined pollution indices, one from lichen $\mathrm{N}+\mathrm{S}$, and one from lichen $\mathrm{Al}+\mathrm{Co}+$ $\mathrm{Cr}+\mathrm{Cu}+\mathrm{Fe}$, were calculated for each lichen site after data conversion, to serve as general indicators for relative local pollution load and to compensate for missing data on individual elements. Site values for other elements were rescaled to $\mathrm{N}$ values with a multiplier: average (across all lichen sites) elemental value/average $\mathrm{N}$ value (Table 3); rescaled elemental ranges were also similar to N. Rescaled values for each element were averaged for the site Index score. The Indices, while moderately correlated with each other $\left(r^{2}=0.465\right)$, reflected somewhat different pollution patterns in the upper range of both Indices (scatter in Fig. 2).

Example scatterplots of elements by species (other scatterplots in Will-Wolf et al. 2017b) illustrate species differences from original data (Fig. 3, left graph), and interspersion of species after conversion (Fig. 3, right graphs). An element is graphed vs the Pollution Index with which it was more strongly correlated. Flacap and Phyaip samples together spanned the full pollution range; only three sites lacked both species. For most species S (Fig 3A, B), Cr (Fig. 3G, H), and $\mathrm{Cu}$ (Fig. 3I, J) elemental values increased with Pollution Index, a pattern also shown by Al, Co, Fe, and N. In contrast, original data for Evemes $\mathrm{S}, \mathrm{Cr}$, and $\mathrm{Cu}$ (Fig. 3A, G, I) leveled off at Pollution Index 1-1.2 and Evemes was absent from the upper Index ranges; pattern was similar for $\mathrm{Al}, \mathrm{Co}, \mathrm{Fe}$, and $\mathrm{N}$. Tight clustering of $\mathrm{S}, \mathrm{Cr}$, and $\mathrm{Cu}$ values partly reflects inclusion in their Index; wide scatter of $\mathrm{Hg}$ and $\mathrm{Ca}$ data reflects weak correlations with the Index (Supplementary 
232 Table 3. Summary of calculations for combined lichen pollution indices.

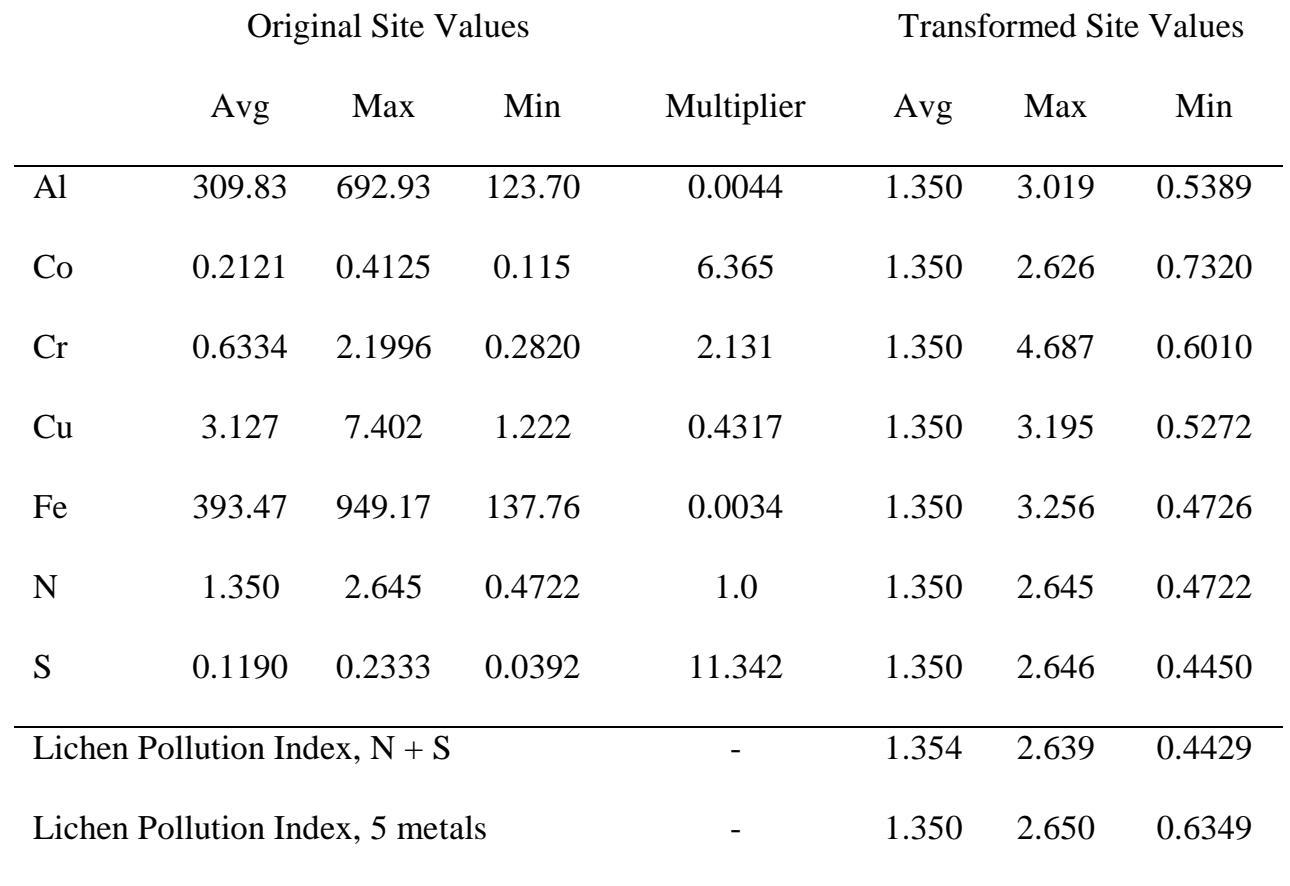

233

234

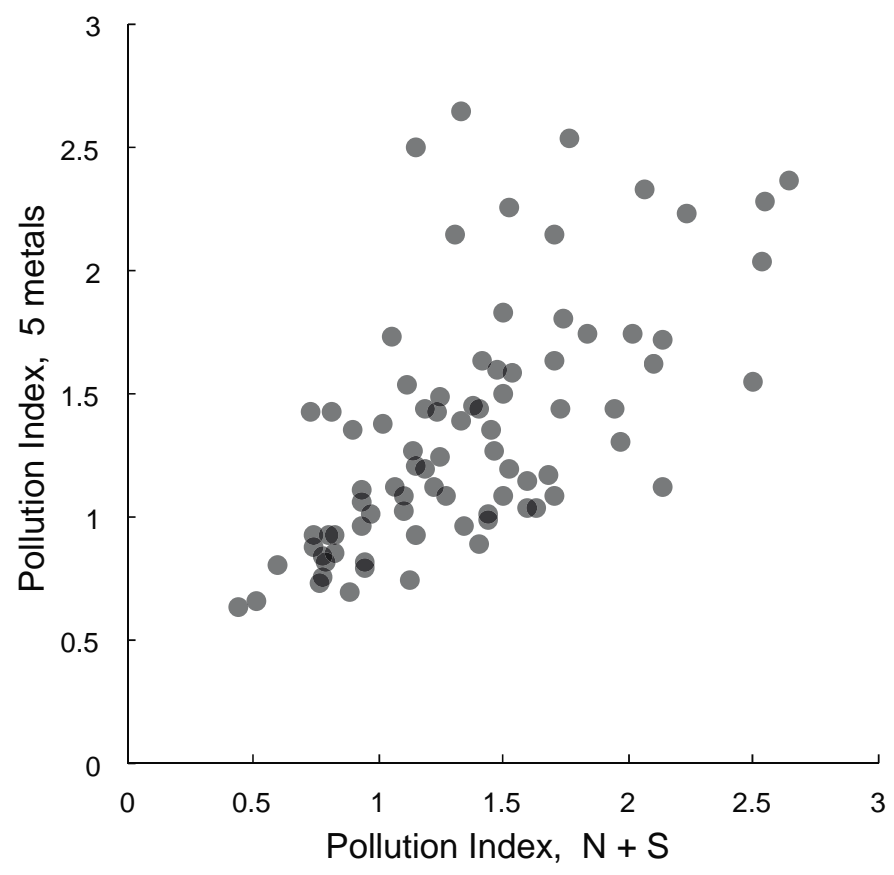

Figure 2. Comparison of the two lichen elemental Pollution Indices. The “...5 metals” Index

237 includes $\mathrm{Al}, \mathrm{Co}, \mathrm{Cr}, \mathrm{Cu}$, and $\mathrm{Fe}$. 
Document 7). Original S (Fig. 3A) and Cr (Fig. 3G) values for species were similar at the same

239 Index score, a pattern shared by Al, C, Fe, and N. Original values for species were more distinct

240 for $\mathrm{Hg}$ (Fig. 3C) and $\mathrm{Cu}$ (Fig. 3I), a pattern shared by Cd, Co, K, Mg, Mn, Na, Ni, P, and Zn.

241 Overlapping original values of Ca (Fig. 3E) for large foliose Flacap and Punrud contrasted with

242 much lower and less variable values for Evemes, Parsul, and Phyaip; $\mathrm{Pb}$ and Sr shared that

243 pattern. Original Evemes (24 samples) values for most pollution elements were below their peaks

244 higher than Flacap values at the same Index score, while Parsul (23), Phyaip (47), and Punrud

245 (25) values for those elements had varied patterns with Flacap (77). Variability increasing with

246 Index score as for $\mathrm{S}, \mathrm{Cr}$, and $\mathrm{Cu}$ was common to most pollution elements. Monitor sites

247 (covering $~ 75 \%$ of Index range in $\mathrm{S}, \mathrm{Cr}$, and $\mathrm{Cu}$ graphs) were for Fig. 3 assigned the average

248 Pollution Index score of the temporary lichen sites near them.

\subsection{Calibration of lichen data to monitor station data}

Correlations between monitor site PM and $\mathrm{N}$ variables for measured pollution and lichen

252

253

254

255

256

257

258

259

260

Figure 3. (next page) Scatterplots for example elements $\mathrm{S}, \mathrm{Hg}, \mathrm{Ca}, \mathrm{Cr}$, and $\mathrm{Cu}$ of original sample data for all lichen species (left column) compared with Flacap data and converted sample data for other species (right column). Samples excluded for conversion were also excluded from graphs in the right column. 

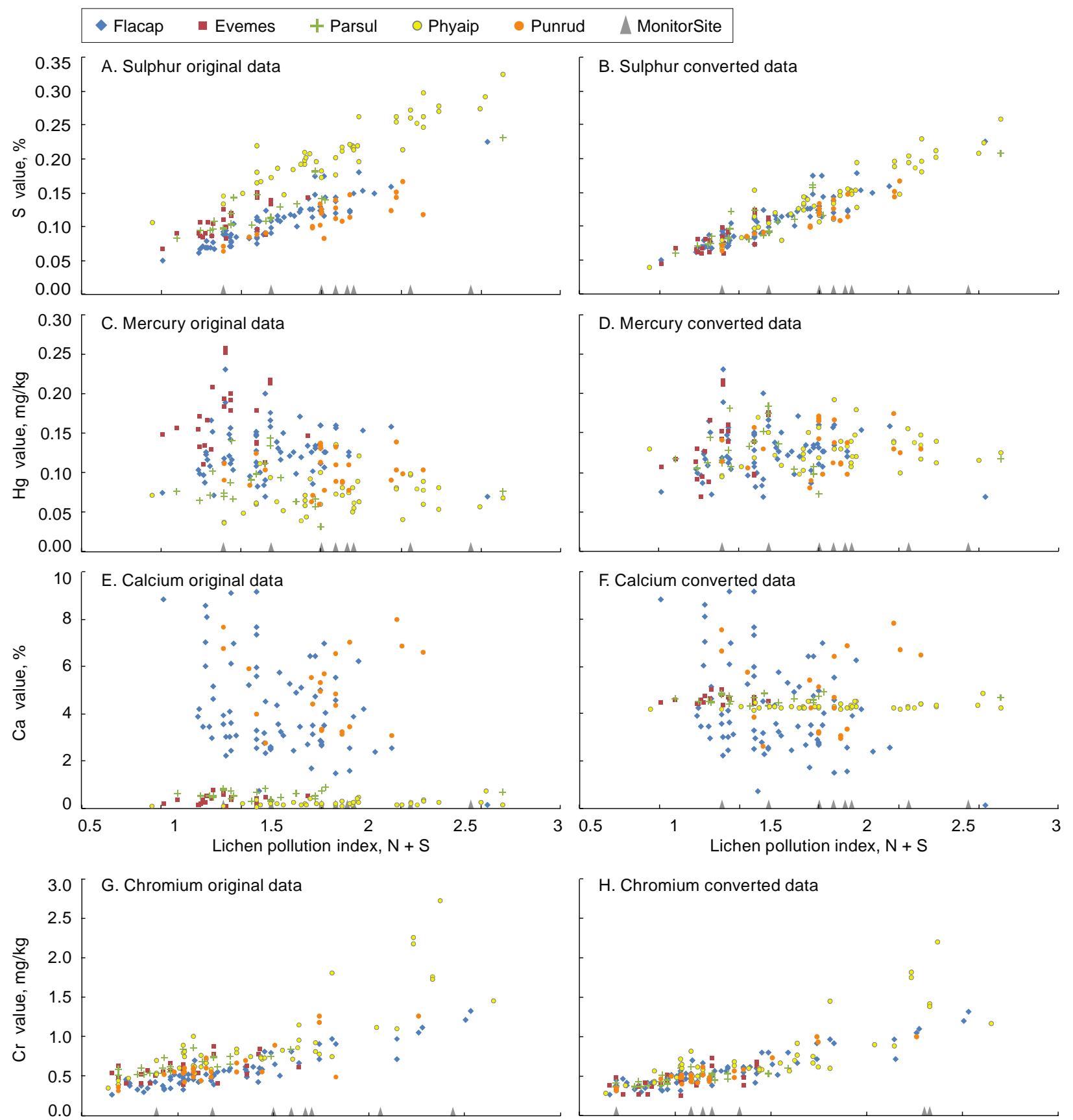

H. Chromium converted data
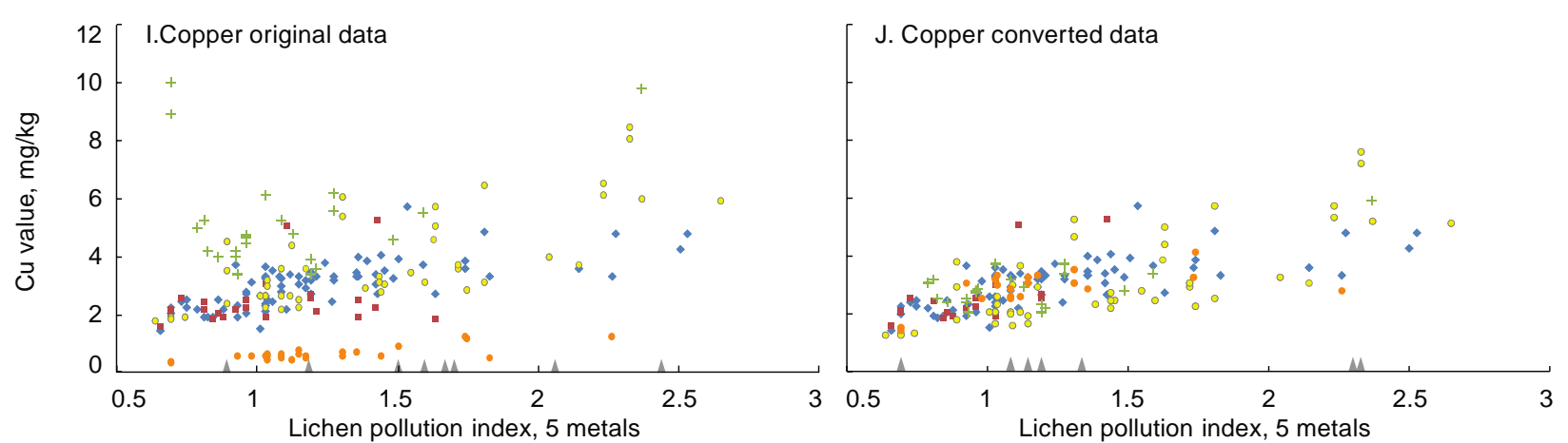
262 with monitor site variables including Mn. Most non-significant results in Table 4 and few

263 positive correlations of a lichen element with its monitor site variable reflect few available

264 monitor sites (Supplementary Document 2). Quantitative calibration of lichen elemental

265 concentrations to measured levels of elements was not attempted because of small sample sizes.

\subsection{Patterns of elemental association and relationship to environment}

The strongest lichen elemental association pattern was the group of local pollution

269

270 elements noted in Section 3.3 and Table 4. Axes 1 and 2 from PCA of sites by elements (Fig. 4) displayed $51 \%$ of variance; each was significant at $\mathrm{p}=0.001$ (Supplementary Document 8).

Similar patterns for $\mathrm{Al}, \mathrm{Co}, \mathrm{Cr}, \mathrm{Cu}, \mathrm{Fe}, \mathrm{N}$, and $\mathrm{S}$ whose pollution origins were supported from correlations with monitor site data (Table 4) were confirmed with PCA and direct simple pairwise correlations (Supplementary Document 7). All had strong negative correlation with PCA Axis 1 (vectors point left); all had strong pairwise correlations from both Flacap samples and site elemental averages. $\mathrm{N}$ and $\mathrm{S}$ were somewhat distinct from the five metals in all analyses (pattern stronger from correlations). Nutrient elements $\mathrm{K}$ and $\mathrm{P}$ were tightly linked both in the PCA (negatively correlated with Axis 2) and from correlations, with Mg loosely linked to them. Each had moderate to weak correlations with the seven local pollution elements. Most other elements were positively correlated with PCA Axis 2, inverse to C; they had weak to no correlations with the local pollution elements, nor with each other. (Supplementary Document 7). Positively correlated $\mathrm{Sr}$ and Ca had negative correlations with most other elements, a pattern not obvious in PCA, but associated with soil dust contamination (Supplementary Document 4). 
284 Table 4. Correlations between monitor site variables and lichen elemental data, Indices, or 285 modeled air pollution. Values of the latter were averages for nearby lichen sites.

Monitor site measured variables (maximum number of sites in parentheses)

Lichen

\begin{tabular}{|c|c|c|c|c|c|c|c|c|c|}
\hline element & $\operatorname{PM}(8)$ & $\mathbf{N}(6)$ & $\operatorname{NOx}(6)$ & $\mathrm{Fe}(5)$ & $\operatorname{Mn}(6)$ & $\mathrm{Pb}(6)$ & $\mathrm{Ni}(6)$ & $\operatorname{Cr}(6)$ & $S(7)$ \\
\hline Co & $.976 * * *$ & $.886^{*}$ & $1.0 * * *$ & 1.0 *** & $1.0 * * *$ & $.957 *$ & $.906^{*}$ & $.900 *$ & $.900^{*}$ \\
\hline $\mathrm{Cu}$ & $.952 * * *$ & $.886^{*}$ & $1.0 * * *$ & $1.0 * * *$ & $1.0 * * *$ & $.943 * *$ & $.970 * *$ & $.917 *$ & $.900 *$ \\
\hline $\mathbf{S}$ & $.952 * * *$ & $.943^{* *}$ & $1.0 * * *$ & $.900 *$ & $.943^{* *}$ & $.886^{*}$ & ns & ns & ns \\
\hline $\mathrm{Cr}$ & $.952 * * *$ & $.943 * *$ & $1.0 * * *$ & $.900 *$ & $.943 * *$ & $.886^{*}$ & ns & ns & ns \\
\hline $\mathbf{N}$ & $.929 * * *$ & $1.0 * * *$ & $.960 * *$ & ns & ns & $.943 * *$ & ns & ns & $.900 *$ \\
\hline $\mathbf{F e}$ & $.919 * *$ & $.884 *$ & $.934 * *$ & $.903 *$ & ns & $.849 *$ & $.952 *$ & $.900 *$ & ns \\
\hline Al & $.913 * *$ & ns & $.841^{*}$ & ns & ns & ns & ns & ns & ns \\
\hline $\mathbf{N a}$ & $.905^{* *}$ & $.886^{*}$ & $.943 * *$ & $.900 *$ & $.900 *$ & ns & $.838 *$ & ns & ns \\
\hline $\mathbf{P b}$ & $.833^{*}$ & $.886^{*}$ & $.943 * *$ & $.900 *$ & $.900 *$ & ns & ns & ns & ns \\
\hline $\mathbf{N i}$ & $.794 *$ & $.943 * *$ & ns & ns & ns & $.929 * *$ & ns & ns & $.929 * *$ \\
\hline $\mathbf{K}$ & ns & ns & $.913 * *$ & ns & ns & $.900 *$ & ns & ns & $.941 *$ \\
\hline Mn & $-.833 *$ & ns & $-1.0 * * *$ & $-1.0 * * *$ & $-1.0 * * *$ & $-.900 *$ & $-.928 *$ & $-.943 * *$ & $-.900 *$ \\
\hline
\end{tabular}

Index,

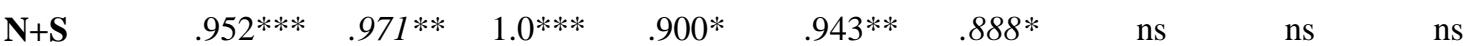

Index, 5

$\begin{array}{llllllllll}\text { metals } & .945 * * * & \mathrm{~ns} & .951 * * & .900 * & .943 * * & .884 * & 1.0 * * * & 1.0 * * * & \mathrm{~ns}\end{array}$

\section{Modeled air pollution}

$\begin{array}{llllllllll}\text { S totdep } & .786^{*} & .882^{*} & \mathrm{~ns} & \mathrm{~ns} & \mathrm{~ns} & .936^{* *} & \mathrm{~ns} & \mathrm{~ns} & 1.0^{* * *}\end{array}$

286 Notes: Spearman rank correlations in standard type; Pearson correlations in italics; numbers in bold indicate a

287 significant correlation between monitor site data and lichen data for the same element.

$288 *=\mathrm{p}<0.04 ; * *=\mathrm{p}<0.01 ; * * *=\mathrm{p}<0.001 ;$ ns=not significant.

289 See Table 1 for modeled air pollution variables, Table 2 for lichen elements, and Supplementary Document 2 for 290 monitor site variables and explanations. 
Lichen elements and monitor site variables absent from this table had no or weak correlations with each other. S totdep had the strongest correlations of modeled pollutant deposition variables.

Relationships of lichen elements with environmental variables in PCA (Fig. 4) were consistent with direct simple and partial correlations between elements and variables (Supplementary Document 1). Pollution Indices accurately reflected pollution element patterns on the PCA, though interpretation of Axis 1 as a pollution gradient was supported primarily by correlations of elements with monitor site variables (Table 4). Modeled N, representing in Fig. 4 all modeled pollution variables, was more strongly linked with geography, climate, and land cover than with lichen pollution elements both in the PCA (correlated more with Axis 2) and from direct pairwise correlations (Supplementary Document 1). Environmental variables were often correlated with each other, but only latitude and temperature were so strongly correlated (negative: $\mathrm{r}^{2} / \mathrm{rho}^{2}=0.86$ to 0.89 ) that they were not entered into the same partial correlations. Temperature and Forest Cover varied along a NE-SW gradient across ecoregions in the study area (Fig. 1), represented mostly on PCA axis 2. Moderate to weak correlations of lichen elements with environmental variables were usually stronger than with modeled pollution variables. Land cover variables had few strong links with elemental values or lichen species, with two exceptions. $\mathrm{Pb}$ had positive simple and partial correlations at $\mathrm{r}^{2}>0.75$ with Developed Land Cover. Flacap was absent from several sites (including Prairie Parkland sites) having low forest cover and moderate Pollution Index scores, as well as from several high Index score urban sites with low forest cover, a pattern not reflected in elemental correlations. Maps of selected variables and lichen elements (Fig. 5) indicate greater air pollution in the more southern and more populated Eastern Broadleaf Forest ecoregion. Modeled total N 


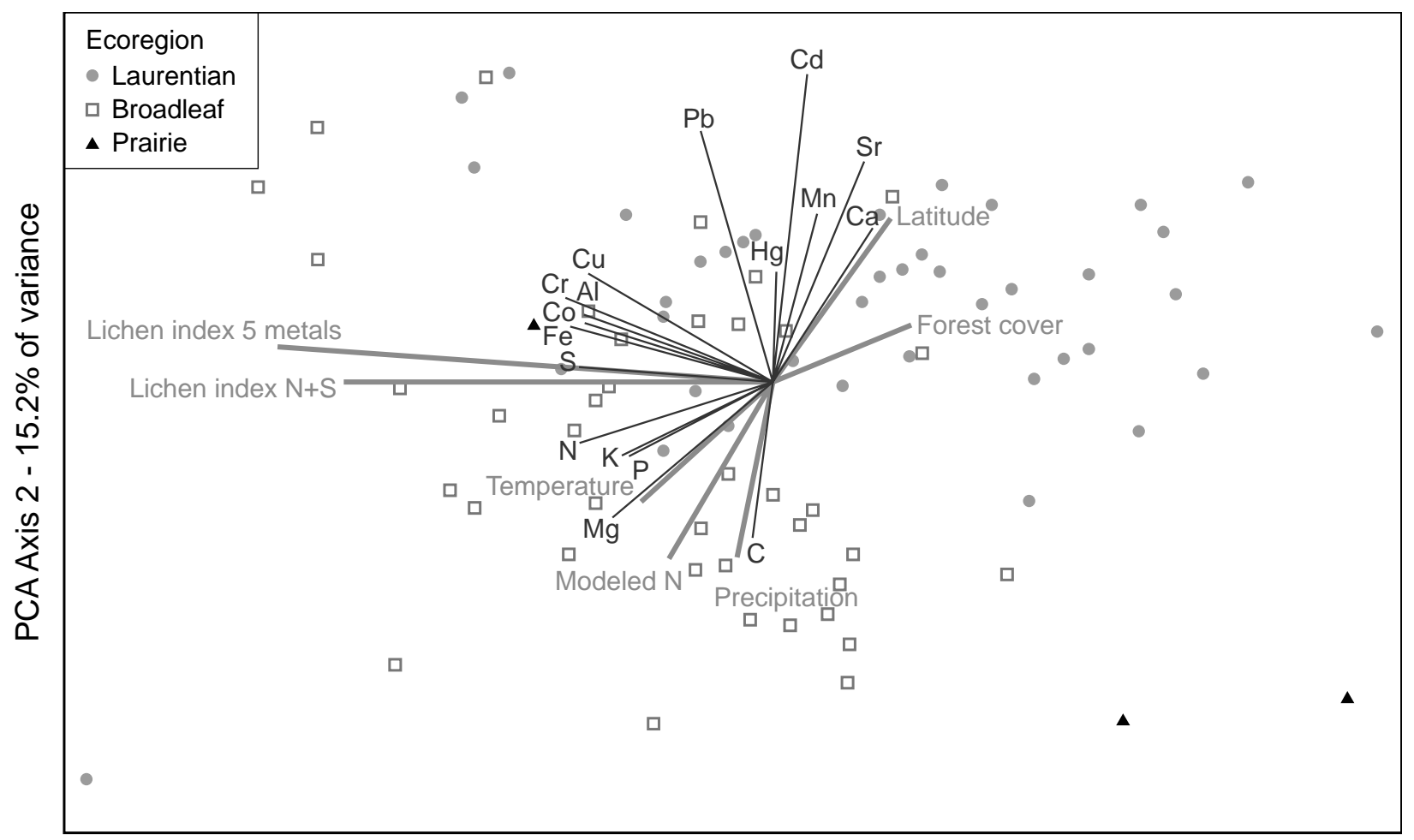

PCA Axis $1-35.6 \%$ of variance

316 Figure 4. Principal components analysis (PCA) of sites by elements. Correlations with Axis 1 of

317 Lichen Index 5 metals $\left(r^{2}=0.77\right)$ and $\mathrm{Cr}\left(r^{2}=0.765\right)$ are similarly strong. Vector scales differ for

318 single elements (thin, blue lines) vs.secondary variables (thick, red lines). Full names of

319 ecoregions in Fig. 1 legend.

deposition (Fig. 5A; modeled $\mathrm{Hg}$ and $\mathrm{S}$ similar) depicts a smoother pattern of local air pollution than do lichen Pollution Indices for $\mathrm{N}+\mathrm{S}$ or pollution metals (Fig. 5B, D-F). Maps confirm

324 conclusions from Fig. 3 that the $\mathrm{N}+\mathrm{S}$ (Fig. 5B) and pollution metals Indices (Fig. 5D-F) differ in geographic pattern. Spatial patterns of lichen Al (Fig. 5D) and $\mathrm{Cu}$ (Fig. 5F) showed the widest

326 variation among those in the Pollution Index, 5 metals (Fig. 5E). Lichen Hg pattern (Fig. 5C)

327 was notably different from other lichen pollution elements or modeled $\mathrm{N}$. 


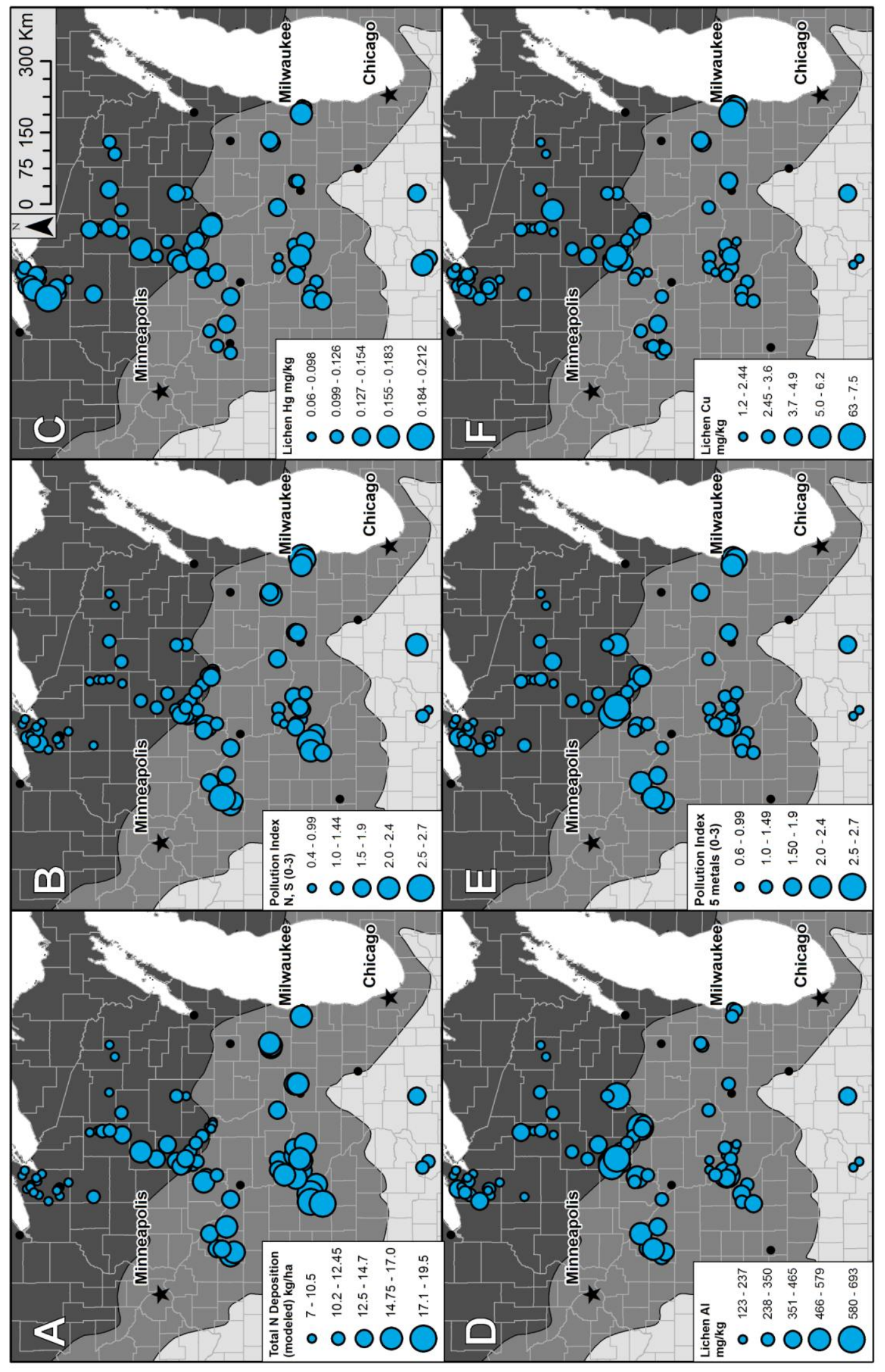


Figure 5 (previous page). Mapped modeled N deposition, lichen Pollution Indices, and selected lichen elements. A. Modeled total N deposition 2013; B. Lichen Pollution Index, N + S; C. Lichen Hg; D. Lichen Al; E. lichen Pollution Index, 5 metals; F. Lichen Cu. Scale bar inset (C) is for all maps. Solid dots are cities; ecoregion shading as in Fig. 1.

\section{Discussion}

\subsection{Bioindicator development as a model for large monitoring programs}

Samples collected across the project area by mostly non-specialist field staff following rigorous protocols supported evaluation of all five lichen species as indicators for local pollution, achieving our first objective. Will-Wolf et al. (2017a) found that relaxed cleanliness protocols and collecting from too few substrates unacceptably reduced data quality. Sample collection time ( $\sim 3 / 4 \mathrm{hr} / \mathrm{site})$, preparation time (1/2-1hr/sample), and elemental measurement cost ( 2013 USA \$50/sample) were acceptable for large-scale application (Will-Wolf et al. 2017b). Validation of measured elements relied on replicates of reference samples as well as standard screening of single measurements; both protocol elements should be routinely included. Field site replicates and laboratory splits (not useful) contributed little to data validation. Data screening for general patterns as well as individual values identified entire samples for exclusion to support quality data analysis; this is recommended for routine analysis. For instance, evaluation of a $\mathrm{Ca} / \mathrm{Sr}$ pattern suggested an unusual soil dust signal and a possible cause for data issues with some excluded samples (Supplementary Document 4, section S4.1). Examination of scatterplots helped visualize conversion needs, samples with odd data to be considered for exclusion, and elements such as Ca whose accumulation patterns might be linked to lichen morphology. 
Data conversion for equivalency among the five lichen species was also successful,

achieving this objective for all species. Reliable models were supported by field site replicates of multiple target species at many sites across the pollution gradient. Exclusion of eligible sites was species-specific; no site was excluded for more than one species pair. Punrud data needed conversion for the fewest elements (13) to equivalence with morphologically similar Flacap. Original $\mathrm{Ca}, \mathrm{Pb}$, and $\mathrm{Sr}$ data overlapped between Punrud and Flacap but differed from the other morphologically distinct species. Elemental accumulation patterns linked with lichen morphology (also Bennett 2008; Bennett \& Wetmore 1997) are consistent with accumulation through passive particle trapping (Bargagli \& Mikhailova 2002; Conti \& Cecchetti 2001; Sloof $\&$ Wolterbeek 1993). Comparisons with two other studies using similar protocols (Will-Wolf et al. 2014, 2015b) suggest that species data conversion may be needed for more elements in large areas with multiple pollution sources (Supplementary Document 9). Specific conversion models were unique to each study, reinforcing their spatial scale- and context-dependence..

Flacap and Phyaip were the two most important target species, between them covering the project region. Easy species recognition by non-specialists helped; their identification success was $\sim 95 \%$ for Evemes, Flacap, or Phyaip and $\sim 70 \%$ for Parsul or Punrud (Will-Wolf et al. 2017a). Evemes data showed saturation of many elements at moderate air pollution loads as estimated from Indexes, and absence at higher loads; similar patterns with other species have been reported by Hauck et al. (2002), Sloof \& Wolterbeek (1993), and Yemets et al. 2014. Evemes pollution sensitivity limits its usefulness for bioindication in the region, despite easy recognition. Parsul and Punrud were also less useful, linked to field staff identification problems; they had few samples, few unique sites, and many sample and data quality issues (Will-Wolf et al. 2017a). Punrud success from expert collectors in two similar studies (Supplementary 
Document 9) suggests collector expertise explains the contrast; the species is common across our project region (Jovan et al. 2017; Brodo et al. 2001). These results supported recommendations for best target species, and improvements to field staff training (Will-Wolf et al. 2017b). Complementary distribution of Flacap and Phyaip sites had several possible causes. Flacap was indeed collected at more low pollution sites and Phyaip at more high pollution sites, consistent with reported sensitivities (e.g. McCune 1988; Showman 1997; Will-Wolf et al. 2015a), but other evidence suggested additional causes. Flacap data did not, like Evemes, exhibit saturation at higher pollution. Our Flacap maxima were lower for most pollution elements than in two similar studies (Supplementary Document 9). Flacap was also not collected, and Phyaip collected, at several study sites in low-forest landscapes with intermediate air quality. Flacap and Phyaip sample distributions in our study are more consistent with the classic "urban drought hypothesis" (Coppins 1973) and recent studies in Europe (e. g. Tretiach et al. 2012) invoking response of Flacap and other species to lower urban humidity (McCarthy et al. 2010). Flacap population declines in part of the study region (Will-Wolf et al. 2011) were more strongly linked to low-forest landscapes than to high air pollution. Links of lower Flacap abundance with forest fragmentation (perhaps related to dispersal limits as well as humidity) need broader evaluation. We were less successful at achieving our objective to calibrate lichen elemental data to monitor site data. Lichen data for elements linked with air pollution were indeed positively correlated with ranks of PM2.5 and N variables from eight air monitor sites. This demonstrated, as others have found (e. g. McMurray et al. 2013; also see section 1), that lichen elements were good proxies to indicate relative local air quality. However, we lacked support to calibrate lichen elemental data quantitatively with instrument-measured data. Only PM2.5 was measured at all monitor sites, while correlations between lichen data and instrument-measured data for that 
element were seldom significant. Sparse availability of costly monitoring sites reinforces the value of lichen bioindicators to represent local air pollution.

Given average within-site variability $<25 \%$ and within-site value ranges $<10 \%$ of full range for converted data from most elements and all species (Supplementary Document 6), variation along a pollution gradient or change over time of 30-35\% of the full gradient should be detectable in our project area by monitoring patterns and trends for the local pollution elements $\mathrm{Co}, \mathrm{Cr}, \mathrm{Cu}, \mathrm{Fe}, \mathrm{N}$, and $\mathrm{S}$, a level of precision useful for large-scale programs. Trends in $\mathrm{Al}$, with higher within-site variability, would need to be stronger for detection. Somewhat weaker patterns and trends should be detectable with the combined Pollution Indices.

\subsection{Indication of air quality in the study region}

We successfully achieved our objective to evaluate lichen-indicated air quality across the study region. Lichen data from both individual elements and combined Pollution Indices clearly indicated a wide range of air quality conditions across the study region. Inclusion of all five lichen species in analyses contributed additional samples to average across within-site variability and better represent local air quality, even though data from only Flacap and Phyaip would have achieved the objective. Weak correlations of modeled air pollution variables with lichen elemental data, plus stronger correlations of the latter with monitor site data, suggest that lichen elemental data represented local air quality notably better than did regionally-modeled pollution variables, a conclusion consistent with other USA studies (Bari et al. 2001; Boquete et al. 2009; Geiser \& Neitlich 2007; Root et al. 2015; Will-Wolf et al. 2014). This is at least partly because the instrument monitoring stations that support air deposition models are widely scattered but over-represent areas of high pollution concern. Different patterns of local distribution for lichen 
$421 \mathrm{~N}$ and $\mathrm{S}$ vs. pollutant metals $\mathrm{Al}, \mathrm{Co}, \mathrm{Cr}, \mathrm{Cu}$, and Fe probably reflected different dispersal modes

422 ( $\mathrm{N}$ and $\mathrm{S}$ in aerosols vs pollution metals in particulates: e. g. Bargagli \& Mikhailova 2002); possibly also some undocumented differences in sources. Composite Pollution Indices captured these differences well and also averaged over data gaps, an advantage for biomonitoring.

Additional patterns for individual elements are summarized here and reviewed in detail in Supplementary Document 4. Lichen $\mathrm{Hg}$ was not well correlated with any other element or environmental variable including modeled $\mathrm{Hg}$ deposition, probably linked to known long residence of $\mathrm{Hg}$ in atmosphere as it disperses from its documented pollution sources (Bargagli 2016). Thus this important pollution element that varies at a more regional scale had no other valid proxy in our study. Lichen Mn data were quite variable, not correlated with other lichen elements reflecting local pollution, and negatively correlated with monitor site data; we recommend, as did Boquete et al. (2011) for mosses, that Mn be excluded from lichen elemental biomonitoring. Lichen $\mathrm{Pb}$ appeared to specifically represent urban impact: it had strong correlations with cover of developed land, the only element strongly linked with land cover. Intensive mapping in urban areas of relative $\mathrm{Pb}$ load from lichen or moss elemental bioindicators could highlight specific subsections with elevated potential risk for more costly instrument monitoring, similar to the Donovan et al. (2016) study.

Our specific research objectives were achieved with classic, relatively simple, widely available, and equally broadly applied data analysis techniques. Their long history facilitates appropriate application and interpretation by applied researchers as well as academic scientists.

\subsection{Applications of general ecological theory to biomonitoring practice}

The ecological context- and scale-dependency (e. g. Levin 1992) of lichen elemental 
444 bioindicators is generally accepted in most modern biomonitoring practice: specific applications

445 and species conversion models are at least by implication recommended for the area and spatial

446 scale used in the study. Performance of bioindicators in the ecological context of the sites

447 studied, and the context of program limitations such as sample collection by non-specialists, are

448 less often addressed in published literature. Including critical details that support interpretation of

449 results in our extensive Supplementary Documents is an acknowledgement of context-

450 dependency useful to include in literature, to support comparisons and improve applications. careful consideration of implications from ecological theory (details in Supplementary Document 4, section S4.2). Both $\mathrm{Al}$ and Fe are strongly supported from our study as local pollution

454 indicators along with $\mathrm{Co}, \mathrm{Cr}, \mathrm{Cu}, \mathrm{N}$, and $\mathrm{S}$ : from correlations with monitor site data (Table 4) and between elements (Supplementary Document 7), and from PCA patterns (Fig. 4). In contrast, 456 in European literature (e. g. Bargagli \& Mikhailova 2002) $\mathrm{Al}$ and $\mathrm{Fe}$ are often interpreted as 457 bioindicators for soil dust contamination. Differences in soil chemistry or air pollutant types do not seem satisfactory explanations, since Europe and E USA have similar temperate forest environments and industrial history. Comparisons with two other E USA studies supported two alternate hypotheses. Invoking simple spatial scale-dependency, $\mathrm{Al}$ and $\mathrm{Fe}$ might have longer

462 (Will-Wolf et al. 2014, 2015b), consistent with the well-documented regional pattern of $\mathrm{Hg}$ 463 distribution (Bargagli 2016). Invoking both multiple causation (e. g. for lichens Ellis \& Coppins 464 2010; Will-Wolf et al. 2006) and more subtle scale-dependency, $\mathrm{Al}$ and Fe might have both soil 465 dust and pollution sources: the dominant signal seen might for instance depend on size of the 466 area studied relative to breadth of the pollution and soil chemistry gradients. 
Evaluation in section 4.1 of multiple factors linked with strong spatial complementarity

of Flacap and Phyaip in our study pointed to nearby forest cover as possibly a stronger driver of the pattern than pollution load. Modern European "urban drought" studies suggested a nonpollution mechanism for absence of Flacap from cities with low forest cover (e. g. Tretiach et al. 2012). This might also apply somewhat to small and isolated rural forests, and dispersal limitation, interacting with response to pollution and humidity, is another possible mechanism linking lichens with landscape pattern (e. g. Ellis \& Coppins 2010) that could be further investigated for bioindicator species. Species in the genus Physcia are well documented as thriving in high nitrogen habitats and microhabitats (e. g. Conti \& Cecchetti 2001; Fenn et al. 2003; Jovan et al. 2012). Our study also suggested Physcia thrives in low-forest landscapes, another pattern deserving more investigation. In another example, proportion of developed land cover was identified in our study as the strongest environmental correlate of $\mathrm{Pb}$ pattern, pointing to urban areas as the most important targets for bioindication with $\mathrm{Pb}$ (Supplementary Document 4). The importance in our study of evaluating links with environmental drivers other than pollution, including some like local land cover whose relevance is not obvious, likely parallels circumstances for any large monitoring program.

\section{Conclusions}

Bioindication with elemental data from in situ naturally-occurring lichens allows both broader coverage and more intense sampling per total program cost than other options, while it represents local air quality better than regionally modeled variables. Biomonitoring with lichen transplants (Bargagli \& Mikhailova 2002; Garty 2002), not practically feasible for large-scale monitoring because it requires costly multiple visits per site and single-source transplants not 
suitable for long climate gradients, has contributed much research about the variation of withinsite responses to be averaged across (considered noise in this context) for generating reliable sitewide signals of pollution load. Reliable site-wide signals support monitoring the health and environmental response of biotic communities across a large region. For instance, estimation of $\mathrm{N}$ critical loads by calibration of site lichen community response to atmospheric $\mathrm{N}$ has been more successful in W USA supported by widespread site-level in situ lichen elemental bioindication (Fenn et al. 2003; Geiser et al. 2010; Jovan et al. 2012) than in E USA (Cleavitt et al. 2015; Pardo et al. 2011, 2015) without such wide support.

Considering multiple environmental factors and appropriate ecological theory such as context- and scale-dependence of patterns at all levels of bioindicator design and interpretation improves application of results. Considering cost-effectiveness is more important for large-scale scientific studies and applications to monitoring, than for small-scale studies. These considerations are important to both support quality science and facilitate continued use of lichen elemental bioindication in large monitoring programs (Ferretti \& Erhardt 2002).

\section{Acknowledgements}

This project was funded by cooperative agreement SRS09-CA1130145101, between the USDA Forest Service Forest Indicator and Analysis Program (FIA) and University of WisconsinMadison. FIA Northern Region Program Managers Dennis May and (acting) Christopher Woodall facilitated planning for the study. FIA Wisconsin crew supervisor Peter Koehler helped organize training and FIA sample collection. FIA Wisconsin crew members John Benaszeski, Benjamin Nurre, Willard Smith, and Sjana Schanning collected field samples on FIA plots and 
513 gave much valuable feedback on training and field methods. Michael Amacher supervised

514 elemental measurement of samples. Wes Hoyer constructed maps in ArcGIS. Sarah Friedrich

515 constructed graphs in Adobe Illustrator.

\section{References}

Bailey, R. G., Avers, P. E., King, T., McNab, W. H. 1994. Ecoregions of the United States. Map. http://www.fs.fed.us/land/pubs/ecoregions/ecoregions.html. Accessed December 2014.

Bargagli, R. 2016. Moss and lichen biomonitoring of atmospheric mercury: A review. Science of the Total Environment 572: 216-231.

Bargagli, R., Mikhailova, I. 2002. Accumulation of inorganic contaminants. Pp. 65-84 in: Nimis, P.L., Scheidegger, C., Wolseley, P. (eds.) Monitoring with Lichens - Monitoring Lichens. NATO Science Series. Kluwer Academic Publishers, The Hague, NL.

Bari, A., Rosso, A., Minciardi, M. R., Troiani, F., Piervittori, R. 2001. Analysis of Heavy Metals in Atmospheric Particulates in Relation to Their Bioaccumulation in Explanted Pseudevernia furfuracea Thalli. Environmental Monitoring and Assessment 69: 205-20.

Bennett, J. P. 2008. Discrimination of lichen genera and species using element concentrations. Lichenologist 40: 135-151.

Bennett, J. P., Wetmore, C. M. 1997. Chemical element concentrations in four lichens on a transect entering Voyageurs National Park. Environmental and Experimental Botany 37: $173-185$.

Boquete, M.T., Fernández, J.A., Aboal, J.R., Real, C., Carballeira, A, 2009. Spatial structure of 
trace elements in extensive biomonitoring surveys with terrestrial mosses. Science of the Total Environment 408: 153-162.

Boquete, M.T., Fernández, J.A., Aboal, J.R., Carballeira, A. 2011. Are terrestrial mosses good biomonitors of atmospheric deposition of Mn? Atmospheric Environment 45: 2704-2710.

Boquete, M.T., Fernández, J.A., Aboal, J.R., Carballeira, A. 2015. Relationship between trace metal concentrations in the terrestrial moss Pseudoscleropodium purum and in bulk deposition. Environmental Pollution 201: 1-9.

Brodo, I. M., Sharnoff, S. D.,Sharnoff, S. 2001. Lichens of North America. Yale University Press, New Haven, Connecticut.

Cercasov, V., Pantelicã, A., Sãlãgean, M., Caniglia, G., Scarlat, A. 2002. Comparative study of the suitability of three lichen species to trace-element air monitoring. Environmental Pollution 119: 129-139.

Cleavitt, N. L., Hinds, J. W., Poirot, R. L., Geiser, L. H., Dibble, A. C., Leon, B., Perron,R., Pardo, L. H. 2015. Epiphytic macrolichen communities correspond to patterns of sulfur and nitrogen deposition in the northeastern United States. Bryologist 118: 304-324.

Cleland, D. T., Freeouf, J. A., Keys, J. E. Jr., Nowacki, G. J., Carpenter, C., McNab, W. H. 2007. Ecological Subregions: Sections and Subsections of the Conterminous United States [1:3,500,000] [CD-ROM]. Sloan, A.M., cartog. General Technical Report WO-76. U.S. Department of Agriculture, Forest Service, Washington, DC.

Conti, M. E., Cecchetti, G. 2001. Biological monitoring: lichens as bioindicators of air pollution assessment—a review. Environmental Pollution 114: 471-492.

Coppins, B. J. 1973. The 'drought hypothesis.' Pp 124-142 in: Ferry, B.W., Baddeley, M.S., Hawksworth, D.L. (eds). Air pollution and lichens. University of Toronto Press, Toronto, 
Ontario, CA.

Donovan, G. H., Jovan, S. E., Gatziolis, D., Burstyn, I., Michael, Y. L., Monleon, V. J., Amacher, M. C. 2016. Using an epiphytic moss to identify previously unknown sources of atmospheric cadmium pollution. Science of the Total Environment 569: 84-93.

Ellis, C. J., \& Coppins, B. J. 2010. Partitioning the role of climate, pollution and old-growth woodland in the composition and richness of lichens epiphytes in Scotland. Lichenologist 42:601-614.[

Fenn, M. E., Baron, J. S., Allen, E. B., Rueth, H. M., Nydick, K. R., Geiser, L., Bowman, W. D., Sickman, J. O., Meixner, T., Johnson, D. W., Neitlich, P. 2003. Ecological effects of nitrogen deposition in the western United States. BioScience 53: 404-420.

Ferretti, M., Erhardt, W. 2002. Key issues in designing biomonitoring programmes. Pp.111-142 in Nimis, P.L., Scheidegger, C., Wolseley, P. (eds.) Monitoring with Lichens Monitoring Lichens, NATO Science Series. Kluwer Academic Publishers, The Hague, NL.

Ferry, B.W., Baddeley, M.S., Hawksworth, D.L. 1973. Air pollution and lichens. University of Toronto Press, Toronto, Ontario, CA.

Frati, L., Brunialti, G., Loppi, S. 2005. Problems Related to Lichen Transplants to Monitor Trace Element Deposition in Repeated Surveys: A Case Study from Central Italy. Journal of Atmospheric Chemistry 52: 221-230.

Gailey, F. A. Y.. Lloyd, O. L. 1986. Methodological investigations into low technology monitoring of atmospheric metal pollution: part 3-the degree of replicability of the metal concentrations. Environmental Pollution (Series B) 12: 85-109.

Gandois, L., Agnan, Y., Leblond, S., Séjalon-Delmas, N., Le Roux, G., Probst, A. 2014. Use of 
geochemical signatures, including rare earth elements, in mosses and lichens to assess spatial integration and the influence of forest environment. Atmospheric Environment 95 (2014) 96-104.

Garty, J. 2002. Biomonitoring heavy metal pollution with lichens. Pp 458-482 in: Kranner, I., Beckett, R. P., Varma, A. K. (ed), Protocols in Lichenology. Culturing, Biochemistry, Ecophysiology and Use in Biomonitoring. Springer-Verlag, Berlin, Germany.

Geiser, L. H., Jovan, S. E., Glavich, D. A., Porter, M. K. 2010. Lichen-based critical loads for atmospheric nitrogen deposition in Western Oregon and Washington Forests, USA. Environmental Pollution 158: 2412-2421.

Geiser, L. H., Neitlich, P. 2007. Air pollution and climate gradients in western Oregon and Washington indicated by epiphytic macrolichens. Environmental Pollution 145: 203-218.

Halleraker, J. H., Reimann, C., de Caritat, P., Finne, T. E., Kashulina, G., Niskaavaara, H. Bogatyrev, I. 1998. Reliability of moss (Hylocomium splendens and Pleurozium schreberi) as a bioindicator of atmospheric chemistry in the Barents region: Interspecies and field duplicate variability. Science of the Total Environment 218: 123-139.

Hauck, M., Mulack, C., Paul, A. 2002. Manganese uptake in the epiphytic lichens Hypogymnia physodes and Lecanora conizaeoides. Environmental and Experimental Botany 48: 107117.

International Atomic Energy Association (IAEA). 2014. Reference Products for Environment and Trade. Reference Materials. Trace Elements \& Methyl Mercury. Website: <http://nucleus.iaea.org/rpst/ReferenceProducts/ReferenceMaterials/Trace_Elements_Me thylmercury/index.htm> Accessed October 2014.

International Union of Pure and Applied Chemistry (IUPAC) 2014. Periodic table of the 
elements. <http://www.iupac.org/> Accessed October 2014.

Jovan, S., McCune, B. 2006. Using epiphytic macrolichen communities for biomonitoring ammonia in forests of the greater Sierra Nevada, California. Water, Air, and Soil Pollution. 170: 69-93.

Jovan, S., Riddell, J., Padgett, P. E.,Nash III, T. H. 2012. Eutrophic lichens respond to multiple forms of N: implications for critical levels and critical loads research. Ecological Applications 22: 1910-1922.

Jovan, S., S. Will-Wolf, L. Geiser, \& K. Dillman. 2017. User guide for the national FIA Lichen database (beta). Draft Gen. Tech. Rep. PNW-GTR-XXX. Portland, OR: U.S. Department of Agriculture, Forest Service, Pacific Northwest Research Station. XXp.

Karakas, S.Y., Tuncel, S. G. 2004. Comparison of accumulation capacities of two lichen species analyzed by instrumental neutron activation analysis. Journal of Radioanalytical and Nuclear Chemistry 259:113-118.

Levin, S. A. 1992. The Problem of Pattern and Scale in Ecology: The Robert H. MacArthur Award Lecture. Ecology 73: 1943-1967.

Loppi, S., Giordani, P., Brunialti,G., Isocrono, D., Piervittori, R. 2002. Identifying deviations from naturality of lichen diversity for bioindication purposes. Pp. 281-284 in Nimis, P.L., Scheidegger, C., Wolseley, P. (eds.) Monitoring with Lichens - Monitoring Lichens, NATO Science Series. Kluwer Academic Publishers, The Hague, NL.

Martin, M.H., Coughtrey, P.J. 1982. Biological Monitoring of Heavy Metal Pollution. Applied Science Publishers, London, UK.

McCarthy, M. P., Best, M. J., Betts, R. A. 2010. Climate change in cities due to global warming and urban effects. Geophysical Research Letters 37: L09705, 
doi:10.1029/2010GL042845.

McCune, B. 1988. Lichen Communities along $\mathrm{O}_{3}$ and $\mathrm{SO}_{2}$ Gradients in Indianapolis. Bryologist 91: 223-228.

McCune, B. \& Grace, J. B. 2002. Analysis of Ecological Communities. MJM Software Design, Gleneden Beach, OR, USA. https://www.pcord.com/book.htm

McCune, B., Mefford, M. J. 2016. PC-ORD. Multivariate analysis of ecological data. Version 6.21. MjM Software Design, Gleneden Beach, OR. <https://www.pcord.com/pcordwin.htm> Accessed June 2016.

McMurray, J. A., Roberts, D. W., Fenn, M. E., Geiser, L. H., Jovan, S. 2013. Using epiphytic lichens to monitor nitrogen deposition near natural gas drilling operations in the Wind River range, WY, U.S.A. Water, Air, and Soil Pollution 224: 1487-1501.

Nimis, P. L., Scheidegger, C., Wolseley, P. (eds.). 2002. Monitoring with lichens-monitoring lichens. NATO Science Series. Kluwer Academic Publishers, The Hague, Netherlands.

Paoli, L., Guttová, A., Grassi, A., Lackovicová, A., Senko, D., Loppi, S. 2014. Biological effects of airborne pollutants released during cement production assessed with lichens (SW Slovakia). Ecological Indicators 40: 127-135.

Pardo, L. H., Fenn, M. E., Goodale, C. L., Geiser, L., Driscoll, C. T., Allen, E. B., Baron, J. S., Bobbink, R., Bowman, W. D., Clark, C. M., Emmett, B., Gilliam, F. S., Greaver, T. L., Hall, S. L., Lilleskov, E. A., Liu, L., Lynch, J. A., Nadelhoffer, K. J., Perakis, S. S., Robin-Abbott, M. J., Stoddard, J. L., Weathers, K. C., Dennis, R. L. 2011. Effects of nitrogen deposition and empirical nitrogen critical loads for ecoregions of the United States. Ecological Applications 21: 3049-3082.

Pardo, L. H., Robin-Abbott, M. J., Fenn, M. E., Goodale, C. L., Geiser, L., Driscoll, C. T., Allen, 
E. B., Baron, J. S., Bobbink, R., Bowman, W. D., Clark, C. M., Emmett, B., Gilliam, F. S., Greaver, T. L., Hall, S. L., Lilleskov, E. A., Liu, L., Lynch, J. A., Nadelhoffer, K. J., Perakis, S. S., Stoddard, J. L., Weathers, K. C., Dennis, R. L. 2015. Effects and Empirical Critical Loads of Nitrogen for Ecoregions of the United States. Ch. 5, pp 129-169 in de Vries, W., Hettelingh, J.-P., Posch, M. (eds.). Critical Loads and Dynamic Risk Assessments, Environmental Pollution 25, Springer Science+Business Media, Dordrecht, The Netherlands. DOI 10.1007/978-94-017-9508-1_5

Puckett, K.J. 1988. Bryophytes and lichens as monitors of metal deposition. In: Nash III, T.H. \& Wirth, V. (eds.) Lichens, Bryophytes and Air Quality. Bibliotheca Lichenologica 30:231267.

Root, H. T., Geiser, L. H., Fenn, M. E., Jovan, S., Hutten, M. A., Ahuja, S., Dillman, K., Schirokauer, D., Berryman, S., McMurray, J. A. 2013. A simple tool for estimating throughfall nitrogen deposition in forests of western North America using lichens. Forest Ecology and Management 306: 1-8.

Root, H. T., Geiser, L. H., Jovan, S. Neitlich, P. 2015. Epiphytic macrolichen indication of air quality and climate in interior forested mountains of the Pacific Northwest, USA. Ecological Indicators 53: 95-105.

Showman, R. E. 1997. Continuing lichen recolonization in the upper Ohio River Valley. The Bryologist 100: 478-481.

Sloof, J. E., Wolterbeek, B, T. 1993. Interspecies comparison of lichens as biomonitors of traceelement air pollution. Environmental Monitoring and Assessment 25: 149-157.

SPSS. 2015. IBM SPSS Statistics. Version 23.0.0. 1989-2015.

Tretiach, M., Pavanetto, M., Pittao, E., Sanità di Toppi L., Piccotto, M. 2012. Water availability 
modifies tolerance to photo-oxidative pollutants in transplants of the lichen Flavoparmelia caperata. Oecologia 168: 589-599.

United States Department of Agriculture, Forest Service [USDA FS]. 2015. Field Guides for Standard (Phase 2) Measurements. V.7.0. U.S. Department of Agriculture, Forest Service, Forest Inventory and Analysis, FIA Library, Field Guides, Methods, and Procedures. http:// http://www.fia.fs.fed.us/library/field-guides-methods-proc/index.php Accessed June 2016.

Vestergaard, N. K., Stephansen, V., Resmussen, L., Pilegaard, K. 1986. Airborne heavy metal pollution in the environment of a Danish steel plant. Water, Air, and Soil Pollution 27: $263-377$.

Will-Wolf, S., Geiser, L. H., Neitlich, P., Reis, A. 2006. Comparison of lichen community composition with environmental variables at regional and subregional geographic scales. Journal of Vegetation Science 17: 171-184.

Will-Wolf, S., Nelsen, M. P., Trest, M. T. 2011. Does morphological response of four common lichen species to pollution, shade, and landscape pattern predict long-term changes in distribution? Pp 375-102 in Bates, S., F. Bungartz, J. Elix, M. Herrera, R. Lücking, A. Zambrano (eds.), Biomonitoring, Ecology, and Systematics of Lichens: Festschrift Thomas H. Nash III. Bibliotheca Lichenologica 106.

Will-Wolf, S., Jovan, S., Nelsen, M. P., Trest, M. T., Rolih, K., Reis, A. 2014. Lichen community indexes for response to climate and air quality in the Midatlantic states, USA. Internal USDA FIA report, October 2014. Available from the authors.

Will-Wolf, S., Jovan, S., Neitlich, P., Peck, J. L. Rosentreter, R. R. 2015a. Lichen-based indexes evaluate responses to climate and air pollution across northeastern U.S.A. Bryologist 118: 
59-82.

698

699

700

701

702

703

704

705

706

707

708

709

710

711

712

713

714

Will-Wolf, S., Makholm, M. M., Nelsen, M. P., Trest, M. T., Reis, A. Jovan, S. 2015b. Element analysis of two common macrolichens supports bioindication of air pollution and lichen response in rural midwestern U.S.A. Bryologist 118: 371-384.

Will-Wolf, S., Jovan, S., Amacher, M. C. 2017a. Lichen elements as environmental indicators: evaluation of methods for large monitoring programs. The Lichenologist. Accepted for publication January 26, 2017.

Will-Wolf, S., Jovan, S., Amacher, M. C. 2017b. Lichen elemental indicators for air pollution in eastern U. S. A. forests; a pilot study in the upper Midwest. Submitted for a USDA Forest Service Pacific Northwest Research Station General Technical Report. PNW-GTR-XXX.

Wolterbeek, B. 2002. Biomonitoring of trace element air pollution: principles, possibilities and perspectives. Environmental Pollution 120: 11-21.

Yemets, O. A., Solhaug, K. A., Gauslaa, Y. 2014. Spatial dispersal of airborne pollutants and their effects on growth and viability of lichen transplants along a rural highway in Norway. Lichenologist 46: 809-823. 